\title{
SURFACE EVALUATION BY X-RAY PHOTOELECTRON SPECTROSCOPY OF HIGH PERFORMANCE POLYIMIDE FOAMS AFTER EXPOSURE TO OXYGEN PLASMA
}

\author{
Orlando Melendez ${ }^{a}$, Michael D. Hampton ${ }^{b}$, Martha K. Williams ${ }^{a}$, \\ Sylvia F. Brown ${ }^{a}$, Gordon L. Nelson ${ }^{c}$, Erik S. Weiser ${ }^{d}$ \\ ${ }^{a}$ NASA, Labs and Testbeds Division, YA-F, Kennedy Space Center, FL 32899, U.S.A. \\ Email: Orlando.Melendez-1@ksc.nasa.gov; Martha.Williams-1@ksc.nasa.gov \\ ${ }^{b}$ Department of Chemistry, University of Central Florida, Orlando, FL 32816 \\ ${ }^{c}$ Florida Institute of Technology, 150 W. University Blvd., Melbourne, FL 32901, U.S.A. \\ bASA, Mail Stop 226, Langley Research Center, Hampton, VA 23681, U.S.A.
}

\begin{abstract}
Aromatic polyimides have been attractive in the aerospace and electronics industries for applications such as cryogenic insulation, flame retardant panels and structural subcomponents. Newer to the arena of polyimides is the synthesis of polyimide foams and their applications. In the present work, three different, closely related, polyimide foams developed by NASA Langley Research Center (LaRC) are studied by X-ray Photoelectron Spectroscopy (XPS) after exposure to radio frequency generated Oxygen Plasma. Although polyimide films exposure to atomic oxygen and plasma have been studied previously and reported, the data relate to films and not foams. Foams have much more surface area and thus present new information to be explored. Understanding degradation mechanisms and properties versus structure, foam versus solid is of interest and fundamental to the application and protection of foams exposed to atomic oxygen in Low Earth Orbit (LEO).
\end{abstract}

Copyright@2002 by the American Institute of Aeronautics and Astronautics, Inc. No copyright is asserted in the United States under Title 17, U.S. Code. The U.S. Government has a royalty-free license to exercise all rights under the copyright claimed herein for Governmental purposes. All other rights are reserved by the copyright owner.

\section{INTRODUCTION}

NASA LaRC has been developing a new and diverse foam technology allowing for the next generation of polyimide foam materials that will be utilized for such things as cryogenic insulation, flame retardant panels and structural sub-components. 1-3 Depending upon the application, foams can be designed and engineered with specific properties from a large number of monomers and monomer blends. These polyimide foams have a number of properties that make them highly desirable materials for use on structures that are exposed to extreme conditions. They are strong, fire resistant, minimally outgassing, stable over a large temperature range, resistant to chemical attack, and can be made in varying densities.

In addressing extreme aerospace conditions, the question of polyimide foam stability and degradation in Low Earth Orbit (LEO) is of interest. Although polyimide films exposure to atomic oxygen and plasma have been studied previously and reported, ${ }^{6,7,12}$ the data relate to films and not foams. The study of polyimide foams versus film behavior is of scientific value. Before utilizing polyimide foams in the aggressive environment of LEO, it is important to understand and predict performance characteristics and the mechanisms of degradation. This information is also important to the protective measures 
which might be required in the utilization of these materials.

The atmosphere at LEO altitudes has a composition that is essentially the reverse of that in the troposphere, $20 \% \mathrm{~N}_{2}$ and $80 \% \mathrm{O}_{2}$. Without the overlying atmosphere to filter short wavelength $U V$ radiation $(<243 \mathrm{~nm})$, the molecular oxygen present is largely photodissociated to atomic oxygen (AO). Atomic oxygen is a highly reactive substance and thus is prone to rapidly oxidize materials exposed to it. Making the situation more extreme is the fact that structures in LEO are typically moving rapidly, as fast as $8 \mathrm{~km} / \mathrm{s}$, to maintain the orbit. Moving at that speed, it is typical for structures to collide with atomic oxygen with an energy of as much as $5 \mathrm{eV}$ and to encounter $10^{15}$ oxygen atoms per $\mathrm{cm}^{2}$ of surface area per second. ${ }^{4}$ In this study, an oxygen plasma generator was utilized to produce an atmosphere of atomic oxygen that would simulate the atmosphere of LEO.

\section{Experimental}

The synthesis of the precursor powders and the fabrication of the foams in this study were reported previously. ${ }^{1-3}$ Three different chemical formulations were used to fabricate the polyimide foams, see Figure 1 and Table 1 for abbreviations and densities. The first letter after TEEK indicates the series and the second letter indicates the density.

The foams were supplied by LaRC and Unitika, Japan. The Kapton ${ }^{\top M}$ tape, 3M Mystic 7362, was obtained from NASA federal stock no. 5970-01-350-5283. The Kapton $^{\mathrm{TM}} \mathrm{HN}$ films, HN 100 (1 mil thick) and HN 200 ( 2 mil thick) were provided by the manufacturer.
Table 1. Foam Materials Description

\begin{tabular}{|l|l|}
\hline $\begin{array}{c}\text { Foam, } \\
\text { Density }\end{array}$ & \multicolumn{1}{|c|}{ Description } \\
\hline $\begin{array}{l}\text { TEEK-HH } \\
(0.082 \mathrm{~g} / \mathrm{cc})\end{array}$ & $\begin{array}{l}\text { ODPA/3,4'-ODA (4,4 } \\
\text { oxydiphthalic anhydride/3,4- } \\
\text { oxydianiline) }\end{array}$ \\
\hline $\begin{array}{l}\text { TEEK-HL } \\
(0.032 \mathrm{~g} / \mathrm{cc})\end{array}$ & $\begin{array}{l}\text { ODPA/3,4'-ODA (4,4 } \\
\text { oxydiphthalic anhydride/3,4- } \\
\text { oxydianiline) }\end{array}$ \\
\hline $\begin{array}{l}\text { TEEK-LL } \\
(0.032 \mathrm{~g} / \mathrm{cc})\end{array}$ & $\begin{array}{l}\text { BTDA/4,4'-ODA (3,3,4,4- } \\
\text { benzophenenone-tetracarboxylic } \\
\text { dianhydride/4,4-oxydianiline })\end{array}$ \\
\hline $\begin{array}{l}\text { TEEK-CL } \\
(0.032 \mathrm{~g} / \mathrm{cc})\end{array}$ & $\begin{array}{l}\text { BTDA/4,4'-DDSO } 2 \text { (3,3,4,4- } \\
\text { benzophenenone-tetracarboxylic } \\
\text { dianhydride/4,4-diaminodiphenyl } \\
\text { sulfone) }\end{array}$ \\
\hline
\end{tabular}<smiles>CC(C)(C)c1cccc(Oc2ccc(N3C(=O)c4ccc(Oc5ccc6c(c5)C(=O)N(C(C)(C)C)C6=O)cc4C3=O)cc2)c1</smiles>

TEEK-HH and HL (ODPA/3,4'-ODA)<smiles>CC(C)(C)c1ccc(Oc2ccc(N3C(=O)c4ccc(C(=O)c5ccc6c(c5)C(=O)N(C(C)(C)C)C6=O)cc4C3=O)cc2)cc1</smiles>

TEEK-LL (BTDA/4,4'-ODA)<smiles>CC(C)(C)c1ccc(OS(=O)(=O)c2ccc(N3C(=O)c4ccc(C(=O)c5ccc6c(c5)C(=O)N(C(C)(C)C)C6=O)cc4C3=O)cc2)cc1</smiles>

TEEK-CL (BTDA/4,4'-DDSO ${ }_{2}$ )

Figure 1, Chemical structures of foams

Surface analyses of samples were performed with a Kratos XSAM X-ray photoelectron (XPS) spectrometer. XPS is a surface analysis technique that looks at the upper atomic layers of a solid surface. In XPS electrons are ejected from a sample surface with a particular binding energy characteristic of the elements present. Shifts in binding energy can be related to oxidation or chemical states. Foam samples were 
typically placed in the sample insertion chamber and allowed to pump down for 1-3 days before analysis. Film samples only required 2-3 hours of pump down time.

The oxygen plasma was generated with a SP1 Plasma Prep II plasma etcher. The Plasma Prep II was operated with an oxygen atmosphere at a feed pressure of 5 psi. The etcher was used at full power for cleaning sample pans and for the initial foam exposure. This etcher utilizes radio frequency, 13.56 $\mathrm{MHz}$, to excite an oxygen atmosphere at a pressure of 2-5 torr into a plasma. This atmosphere will contain some undissociated oxygen molecules, oxygen ions, electrons, and oxygen atoms. For this work, the atmosphere was considered to consist of oxygen atoms only and the terms, oxygen plasma and atomic oxygen will be used interchangeably.

The effective atomic oxygen flux was determined, using the following procedure, ASTM E2089-00, Standard Practices for Ground Laboratory Atomic Oxygen Interaction Evaluation of Materials for Space Applications at $100 \%, 50 \%$ and $25 \%$ power levels. ${ }^{5}$ Samples of Kapton ${ }^{\mathrm{TM}}$ tape, roughly 1$2 \mathrm{~cm}$ square, were placed in cleaned aluminum sample pans, mastic side down, and weighed. Samples were then individually placed in the etcher and exposed to oxygen plasma for 30 min periods at the desired power level. After each $30 \mathrm{~min}$ period the samples were weighed. Analyses were run in triplicate at each power level. The effective atomic oxygen flux, F, was then calculated according to the following equation in which $\Delta \mathrm{M}$ is the mass loss of the sample in grams, $\rho$ is the density in $\mathrm{g} / \mathrm{cm}^{3}, \mathrm{~A}$ is the sample surface area in the $\mathrm{cm}^{2}, \mathrm{E}$ is the in-space erosion rate of Kapton $^{\mathrm{TM}}, 3 \times 10^{-24} \mathrm{~cm}^{3} /$ Oxygen atom and $\mathrm{t}$ is time in seconds:

$$
F=\Delta M /(\rho A E t)
$$

The effective atomic oxygen flux distribution over the placement of the samples (front, middle, and rear) were determined by using 4 samples of Kapton ${ }^{\mathrm{TM}} \mathrm{HN}$ film mounted to the cleaned sample cups with a very small piece of carbon tape. The tape was situated such that the sample covered and protected it. The Kapton ${ }^{\mathrm{TM}} \mathrm{HN}$ film samples were placed in the 4 positions within the etcher that were used for foam exposures and the flux determined as above. When the samples were removed from the etcher for weighing, they were kept in a nitrogen atmosphere to exclude atmospheric oxygen and moisture interference. Data indicated that the effective atomic flux was distributed consistently throughout the chamber.

The foam samples were cut into $2 \times 2 \mathrm{~cm}$ squares. Foams were placed in a reduced pressure environment to reduce the amount of absorbed moisture before initial weighing. After obtaining baseline XPS data, they were exposed to oxygen plasma at $25 \%$ power for $30 \mathrm{~min}$ increments and weighed after each exposure. When significant weight loss occurred, samples were re-analyzed with XPS, and then oxygen plasma exposure continued.

\section{RESULTS AND DISCUSSION}

Figure 3 indicates the effective oxygen flux versus time at $25 \%$ power for the Kapton ${ }^{\mathrm{TM}}$ witness coupon ran with the foam samples. The average effective oxygen flux is $1.14 \times 10^{16} \mathrm{O}$ atom $/ \mathrm{cm}^{2}$.s.

In addressing the interactions and reactivity of these foams with atomic oxygen it is to be noted that although the structures are very similar (see Figure 1), there are some important differences. Both the $\mathrm{C}$ and the $\mathrm{L}$ series foams have a carbonyl group linkage in the dianhydride groups, while the $\mathrm{H}$ series 
foams have an ether linkage. In the $\mathrm{L}$ series foams, the diamine portion has oxygen parabonded in both benzene rings, while in the $\mathrm{H}$ series foams, the right most benzene ring is meta bonded. In the $\mathrm{C}$ series foams the diamine has an $\mathrm{SO}_{2}$ linkage. In previous thermal degradation studies of polyimide films, the diamine structure (Figure 2) appears to have a greater influence on the stability, with the ranking being $\mathrm{SO}>\mathrm{SO}_{2}>\mathrm{CH}_{2}>\mathrm{O}$ for $\mathrm{X}^{10}$

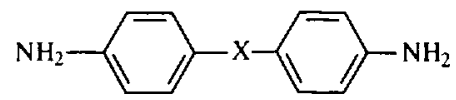

Figure 2, Generic Chemical Structure for Diamine

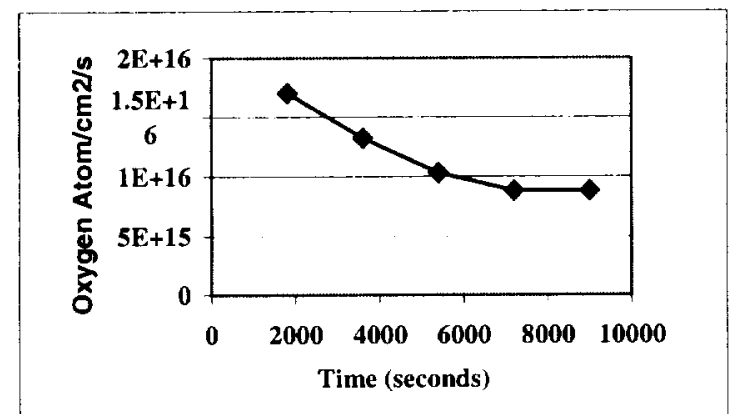

Figure 3, Atomic Oxygen flux versus time at $25 \%$ power for Kapton ${ }^{\text {TM }}$ Witness Coupon

Preliminary analyses indicate that the samples had a small mass loss for the first hour of oxygen plasma exposure and then began a more rapid weight loss. The CL sample with the $\mathrm{SO}_{2}$ linkage in the diamine has the greatest resistance to weight loss.

Figure 4 includes the mass loss of the HL, HH, LL series, plus Kapton ${ }^{\mathrm{TM}}$. The mass loss of the HL series is the greatest, followed by $\mathrm{HH}$, although that is of a higher density than the LL series. Here the mass loss appears to be more dependent upon chemistry versus density. Because of their different densities and their chemistries not containing an $\mathrm{SO}_{2}$ linkage, only the $\mathrm{H}$ and $\mathrm{L}$ series were chosen to be studied further by High Resolution XPS to investigate the relationships of density and chemistry to atomic oxygen effects. High Resolution XPS is capable of separating/resolving different oxidation states or binding energies.

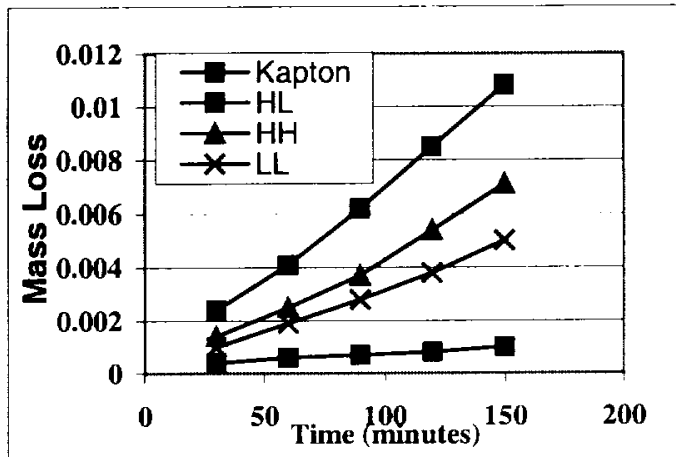

Figure 4, Mass Loss of TEEK HL, HH, LL \& Kapton ${ }^{\top M}$ Tape

\section{High Resolution XPS Data}

A high-resolution spectra baseline was obtained for each of the three polymers, $\mathrm{HH}$, HL and LL before and after plasma exposure (see Figure 5, (a) $\rightarrow$ (e) for Cls peaks). The spectra were acquired in the small aperture XPS mode for higher resolution using magnesium X-rays at $12 \mathrm{KV}$ and $12 \mathrm{~mA}$. Following the initial baseline characterization by XPS the samples were exposed to oxygen plasma for 2.5 hours. A second XPS spectrum was obtained for each sample after the plasma exposure. The XPS results are summarized in Table 2. The carbon peak shows two main features, one is a peak with binding energy (BE) around $284.8 \mathrm{eV}$ (designated $\mathrm{C}-1$ in Table 1), and a second peak with binding energy around $288 \mathrm{eV}$ (designated $\mathrm{C}-2$ in Table 1). The peak $\mathrm{C}-1$ at $284.8 \mathrm{eV}$ results from signals due to $\mathrm{C}-\mathrm{C}, \mathrm{C}-\mathrm{N}$ and $\mathrm{C}-\mathrm{O}$ bonds. 
Table 2, XPS Data

\begin{tabular}{|c|c|c|c|c|c|c|c|c|c|c|}
\hline \multirow{3}{*}{$\begin{array}{l}\text { Sample } \\
\text { I.D. }\end{array}$} & \multicolumn{5}{|c|}{ Carbon } & \multicolumn{5}{|c|}{ Oxygen } \\
\hline & \multirow{2}{*}{ Peak } & \multicolumn{2}{|c|}{ Baseline } & \multicolumn{2}{|c|}{$\begin{array}{l}\text { After Plasma } \\
\text { Exposure }\end{array}$} & \multirow{2}{*}{ Peak } & \multicolumn{2}{|c|}{ Baseline } & \multicolumn{2}{|c|}{$\begin{array}{l}\text { After Plasma } \\
\text { Exposure }\end{array}$} \\
\hline & & $\begin{array}{c}\mathrm{BE} \\
(\mathrm{eV})\end{array}$ & $\begin{array}{c}\text { Atomic } \\
\%\end{array}$ & $\begin{array}{c}\mathrm{BE} \\
(\mathrm{eV})\end{array}$ & $\begin{array}{c}\text { Atomic } \\
\%\end{array}$ & & $\begin{array}{c}\mathrm{BE} \\
(\mathrm{eV})\end{array}$ & $\begin{array}{c}\text { Atomic } \\
\%\end{array}$ & $\begin{array}{c}\mathrm{BE} \\
(\mathrm{eV}) \\
\end{array}$ & $\begin{array}{c}\text { Atomic } \\
\%\end{array}$ \\
\hline \multirow{3}{*}{$\underline{\mathrm{HH}}$} & C 1s & 284.8 & 70.11 & 284.8 & 55.75 & O Is & 533 & 29.89 & 532.3 & 44.25 \\
\hline & $\mathrm{C}-1$ & 284.6 & 43 & 284.7 & 81.3 & & & & & \\
\hline & $\mathrm{C}-2$ & 286.6 & 57 & 288.7 & 18.69 & & & & & \\
\hline \multirow{3}{*}{$\underline{\mathrm{HL}}$} & C 1s & 284.7 & 76.46 & 284.6 & 48.7 & O 1s & 532 & 20.43 & 532.2 & 48.7 \\
\hline & $C-1$ & 284.7 & 91.19 & 284.5 & 67.8 & & & & & \\
\hline & $C-2$ & 288.1 & 8.81 & 288 & 32.2 & & & & & \\
\hline \multirow{3}{*}{$\underline{\text { LL }}$} & $\mathrm{C} 1 \mathrm{~s}$ & 284.8 & 74 & 284.9 & 56.15 & O Is & 532 & 24 & 532.7 & 43.85 \\
\hline & $C-1$ & 284.8 & 92.7 & 2847 & 61.3 & & & & & \\
\hline & $\mathrm{C}-2$ & 288 & 7.22 & 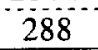 & 38.7 & & & & & \\
\hline
\end{tabular}

*atomic \% does not include nitrogen

$\Varangle \mathrm{C}-1$ and $\mathrm{C}-2$ represent $100 \%$ of $\mathrm{Cls}$

The peak $\mathrm{C}-2$ at $288 \mathrm{eV}$ represents the carbonyl group $\mathrm{C}=\mathrm{O} .^{11}$ Of the three samples, sample HH shows the highest initial amount of oxygen, almost $30 \%$ compared to $20.4 \%$ for $\mathrm{HL}$ and $24 \%$ for LL (see also Figure 5). The higher initial oxygen content for $\mathrm{HH}$ is related to the high signal due to the $\mathrm{HH}$ carbon peak $\mathrm{C}-2$. This is the peak from the carbonyl $\mathrm{C}=\mathrm{O}$. $\mathrm{HH}$ has a larger carbonyl signal than $\mathrm{HL}$ or LL even though sample LL has one more carbonyl group. The reason for the larger carbonyl signal for $\mathrm{HH}$ is that the density of $\mathrm{HH}$ is two and a half times the density of $\mathrm{HL}$ and LL. This implies that a similar unit of volume will contain one basic unit of LL with 5 carbonyl groups. The same unit of volume will contain two and a half unit of $\mathrm{HH}$ with a total of 10 carbonyl groups

All three samples showed significant increases in oxygen with a comparable reduction in carbon. These results indicate that the sample is loosing carbon while at the same time some oxygen is been incorporated to the molecule. In a series of molecular beam-surface scattering experiments on Kapton ${ }^{\top M}$, Minton et al. ${ }^{6}$ reported $\mathrm{CO}$ and $\mathrm{CO} 2$ as the main volatile species during atomic oxygen attack. Although there is an overall decrease in carbon (see Figure 5, charts after plasma exposure), samples HL and LL showed a significant increase in $\mathrm{C}-2$ corresponding to carbonyl, $\mathrm{C}=\mathrm{O}$ relative to the peak $\mathrm{C}-1$. This is consistent with results reported in several papers. A study by Cross et. al. ${ }^{7}$ of the interaction of atomic oxygen with a Kapton ${ }^{\mathrm{TM}}$ film, found $\mathrm{H}_{2}, \mathrm{H}_{2} \mathrm{O} \mathrm{CO}$, and $\mathrm{CO}_{2}$ in the gas phase reaction products. They also found more carbonyl-bonded oxygen. The increase in carbonyl was also observed by Lu et. al. ${ }^{8}$ after using Pulsed UV laser irradiation on a polyimide film. Kitching et. al. ${ }^{9}$ in an XPS study of biomedical polyurethane modified by oxygen plasma, also observed an increase in carbonyl following the plasma treatment.

Sample HH also showed a significant increase in oxygen with a comparable overall reduction in carbon. However, contrary to samples HL and LL and results for Kapton in the literature, the carbonyl groups were reduced, (C-2 less than $\mathrm{C}-1$ after exposure). Again, it seems that the high density of $\mathrm{HH}$ plays an important role. A higher density 
implies that there are more $\mathrm{C}=\mathrm{O}$ bonds exposed to the plasma than in HL and LL. The results showing a reduction in carbonyl seems to indicate that the plasma is reacting with this group preferentially over atoms in the ring structure resulting in some volatile products. The opposite seems to occur in samples HL and LL where the attack by the plasma seems to take place at sites on the ring resulting in the addition of oxygen at those locations.

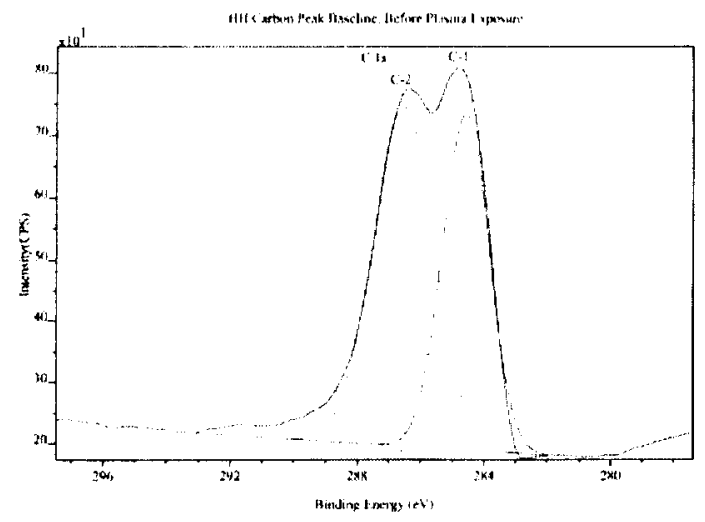

(a) TEEK-HH Before Plasma

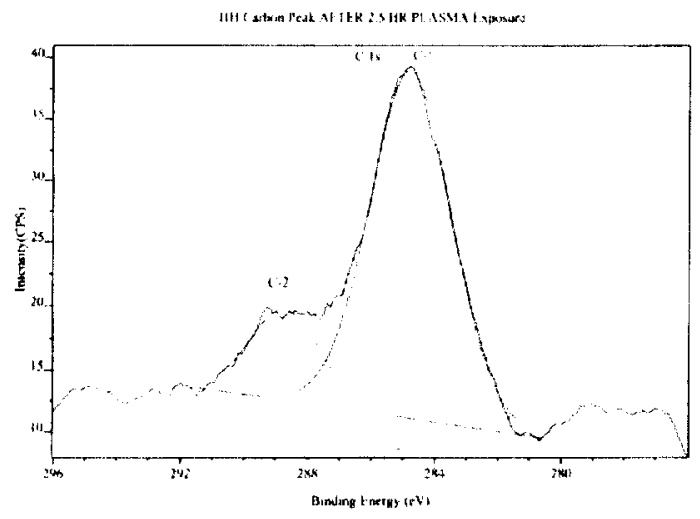

(b) TEEK-HH After Plasma

Figure 5, XPS Spectra, Before and After Plasma Exposure for $\mathrm{HH}(a-b), L L(c-d), \&$ $H L(e$, before $)$

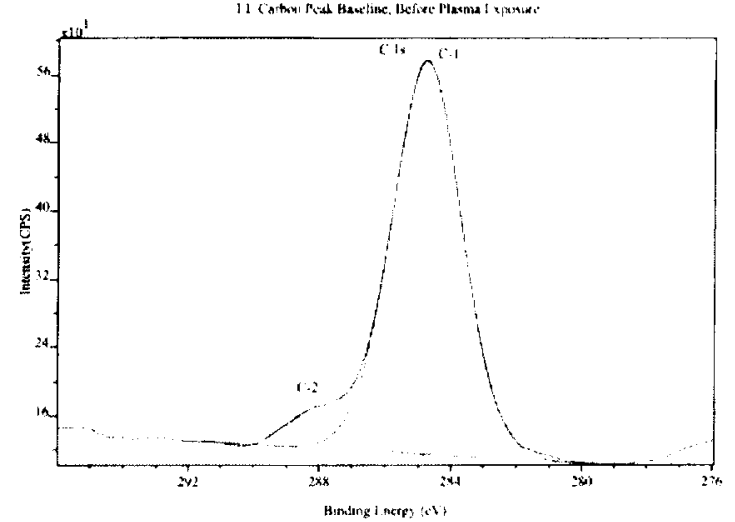

(c) TEEK-LL Before Plasma

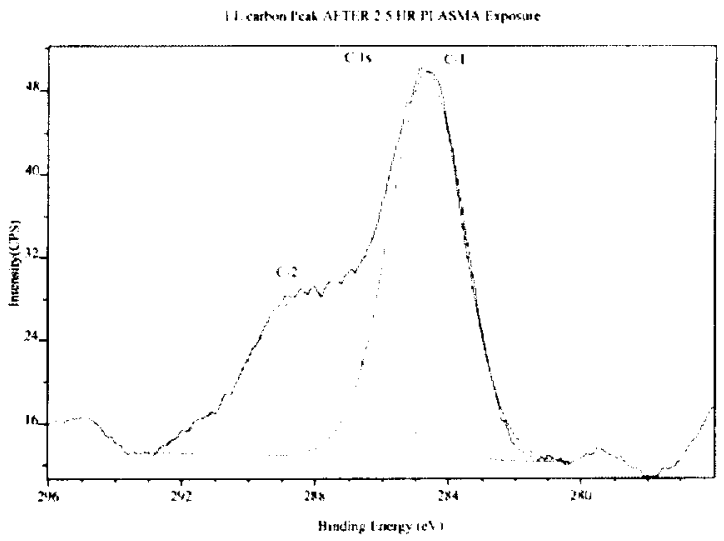

(d) TEEK-LL After Plasma

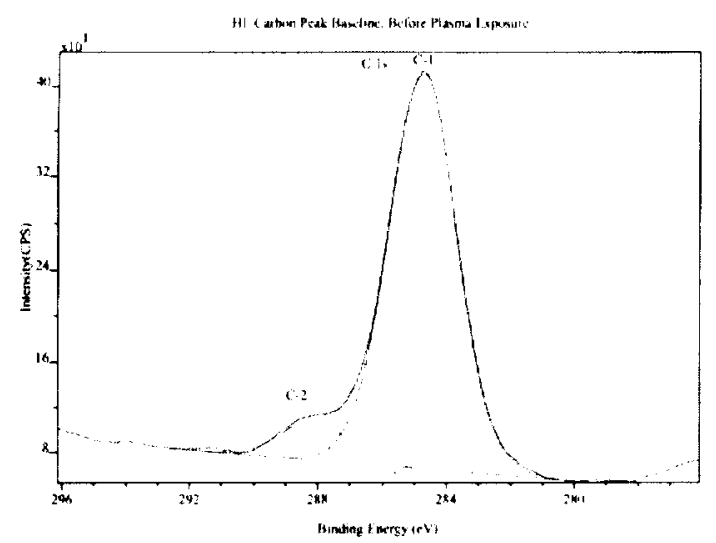

(e) TEEK-HL Before Plasma

*After Plasma exposure chart follows trend observed in LL series 


\section{CONCLUSIONS}

As indicated in previous reports, ${ }^{2.3}$ data presented validate that newly developed polyimide foams are high performance polymers in mechanical, physical and thermal properties. In those reports, the TEEK-C ${ }^{2,3}$ series proved to be more thermally stable, and in preliminary data discussed in this report, the $\mathrm{C}$ series also appear to have the greatest resistance to atomic oxygen with the least amount of mass loss on exposure.

The mass loss data indicates that chemical structure and then density appear to play the greatest role on atomic oxygen resistance for the HH, HL and LL series. The XPS data indicates an overall oxidation of the foams. The data presented on the HL and LL foams showing an increase in carbonyl after atomic oxygen exposure correlate with the data previously reported on polyimide films. The higher density $\mathrm{HH}$ series showed a decrease in the carbonyl group. This seems to indicate that the plasma is reacting with this group preferentially over atoms in the ring structure resulting in some volatile products.

\section{ACKNOWLEDGMENTS}

The authors would like to thank NASA, Kennedy Space Center, and the National Space Club/Hugh L. Dryden Memorial Fellowship for doctoral study support of Ms. Williams.

This document was prepared under the sponsorship of the National Aeronautics and Space Administration. Neither the United States Government nor any person acting on behalf of the United States Government assumes any liability resulting from the use of the information contained in this document, or warrants that such use will be free from privately owned rights. The citation of manufacturer's names, trademarks, or other product identification in this document does not constitute an endorsement or approval of the use of such commercial products.

\section{$\underline{\text { REFERENCES }}$}

1. Hou, T.H.; Weiser, E.S.; Siochi, E.J.; St. Clair, T.L. and Grimsley, B.W., Processing and Properties of Polyimide Foam, $44^{\text {th }}$ International SAMPE Symposium, 1999, 1792-1806.

2. Weiser, E.S.; Johnson, T.F.; St. Clair, T.L.; Echigo, Y.; Kaneshiro, H.; Grimsley, B., High Temperature Polyimide Foams for Aerospace Vehicles, Journal of High Performance Polymers, March 2000, 12, 1, 1-12.

3. Williams, Martha K., et al., High Performance Polyimide Foams, G. L. Nelson and C. A. Wilkie, eds., Fire and Polymers: Materials and Solutions for Hazard Prevention, ACS Symposium Series 797, American Chemical Society/Oxford Press, 2001, 49-62.

4. Caledonia, G.E.; Krech, H.R.; Studies of the Interaction of $8 \mathrm{~km} / \mathrm{s}$ Oxygen Atoms, Materials Degradation in Low Earth Orbit (LEO), Edited by Srinivasan, V.; Banks, B.A.; 1990.

5. ASTM E 2089-00, Standard Practices for Laboratory Atomic Oxygen Interaction Evaluation of Materials for Space Applications.

6. Minton, T.K.; Seale, J.W.; Garton, D.J.; Zhang, J.; Mechanisms of Polymer Erosion in Low Earth Orbit: Implications For Ground-based Atomic Oxygen Testing, $44^{\text {th }}$ International SAMPE Symposium, 1999, 1051-1063. 
7. Cross, J.B., S.L., Koontz; Gregory, J.C., and Edgell, M.J., Hyperthermal Atomic Oxygen Reactions with Kapton and Polyethylene, Materials Degradation in Low Earth Orbit (LEO), Edited by Srinivasan, V.; Banks, B.A.; 1990, 1-13.

8. Lu, Q. H.; Li, M.; Zhu, Z.; Wang, Z.; Polymide Surface Modification by Pulsed Ultraviolet Laser Irradiation with Low Fluence, Journal of Applied Polymer Science, 2001, Vol. 82, 2739-2743.

9. Kitching, K.J., Wilson, D.J.; Doherty, P.J.; Williams, R.L.; An X-ray Photoelectron Spectroscopy Study of Biomedical Polyurethane Modified Using Low-Power Plasma, Journal of X-ray Science and Technology, 2001, V.9, 7783.

10. Cella, J.A.; Degradation and Stability of Polymides (Polyimides), Marcel Dekker, Inc., New York., 1996, 343-365.

11. Briggs, D.; Beamson, G.; Primary and Secondary Oxygen-Induced Cls Binding Engergy Shifts in X-ray Photoelectron Spectroscopy of Polymers, Anal. Chem. 1992, 64, 1729-1736

12. Snyder, A.; Investigation of Atomic Oxygen Erosion of Polyimide Kapton $\mathrm{H}$ Exposed to a Plasma Asher Environment, $44^{\text {th }}$ International SAMPE Symposium, 1999, 1321-1326. 